concern for learning how to cope with the immutable issues of inequality. The authors all examine the contention that equality should be the primary objective of the health service. The common theme is that there are no ready-made criteria for acceptable and unacceptable inequalities. All of the essays suggest that the issues of inequality should be approached in an incremental, pragmatic fashion, and dealt with when and if society becomes concerned about them. Rudolf Klein and Peter Collison present the difficulties of establishing which inequalities are important. Given that there are differences in health status caused by biological or social differences, what quantities of resources should be brought to bear to reduce these differences? A J Culyer considers the issues raised by the assertion that we are born with unequal chances of good health (however defined), and examines alternative methods for allocating resources. Robert Pinker puts forward a convincing case for the promotion of consumer choice, through a mixture of public and private health systems, given that all inequalities are inerradicable. Taken together, the arguments of the four professors suggest that theoretical concerns about equality are not relevant to the present making of health policy. There is much that can be done without having to revert to the need for clearly defined social welfare functions in health-policy making.

Now that the NHS is settling down to its new management philosophy, it is time to return to the policy questions and to address them in the context of the general management. Acceptable Inequalities is a useful beginning for the much needed new thinking in this area.

\section{ELLIE SCRIVENS \\ Lecturer in Public Sector Management London Business School Sussex Place, Regents Park London NWI 4SA}

\section{Stress:}

\section{The Challenge to Christian caring}

Gaius Davies, 287 pages, Eastbourne, £6.95, Kingsway, 1988

The author of this book is a consultant psychiatrist at a London (teaching) hospital and a practising Christian. His book is primarily addressed to a lay readership and addresses the belief held

by some Christians that if you have a faith in God then you should be immune to the effects of stress and have no need of help from drugs or professional carers. In arguing against this position Davies shows the need for a true partnership between a supportive Christian community and those who offer professional help via the accurate diagnosis and appropriate treatment of physical and psychological problems.

Whilst this book does not fall naturally into the category of 'ethics' nevertheless it does, by implication, underline the importance of autonomy, partnership and respect of the individual and his/her personal value system. Failure to recognise the patient's basic premise regarding 'Godgiven' immunity from stress can result in the person feeling guilty and sinful for having fallen from what some would regard as expected Christian behaviour.

Davies illustrates well that the wholeperson approach is not only a reminder to clinicians and others to respect the spiritual aspect of the person but is also a prompt to the community of faith not to ignore the body and mind and the care available in good clinical practice. The various chapters in this book cover a wide variety of forms of stress ranging through loss, sadness, personality problems, conscience, sex and old age to a variety of forms of mental illness and 'breakdown'.

This book will be of interest to those who offer pastoral care within a Christian context and argues very persuasively for a healthy partnership and the right use and assessment of what help can be offered both spiritually and medically. There is much helpful advice for those seeking to distinguish between expressions of spirituality and those requiring clinical diagnosis and treatment: as in the case of exorcism or conversion phenomena.

PETER W SPECK Chaplain Royal Free Hospital London

\title{
The Physician as Captain of the Ship
}

\section{N M P King, L R Churchill and A W Cross, 254 pages, Dordrecht, $£ 44.00$, D Reidel, 1988}

This book is a collection of twelve thoughtful essays, chiefly by authors from American departments of social medicine or ethics. They discuss the current uneasy relationship between doctors and their patients on the on hand, and nurses, paramedical staff and? administrators on the other. They all agree that changes are occurring, and? that doctors must ensure that these changes are not detrimental to healtho care. Thus for instance, some Americares hospital administrators press doctors to maximise the income for a hospital by concentrating on profitable medicine. Doctors are urged everywhere in this book to become involved in the decisions of administrators, or to take $\vec{\omega}$ on administrative roles themselves.

These delicate subjects are apposite to today's problems here in the NationaP Health Service, for we also are beinger encouraged to become hospitafu managers and budget holders, to examine the costs of what we are doing, and to take part in vigorous clinica? audit. These influences are a reflection of changes in society, and so doctors, we are told, must change or be changed. Of until, as one essayist describes it in the nautical metaphor running through this book, 'the physician's grip is wrested from the tiller and chained to the oars' In an essay on the changing roleco $f$ nurses in hospitals, it is pointed out topa before 1900 doctors were not m\&s involved in the running of hospitas which was then the duty of boards of trustees. Only when more patients wer admitted to hospitals for surgicad procedures did the doctors seek tō influence hospital management and spending.

The other area extensively discussed is the relationship between doctors as 'captains' and other professional staff ${ }_{2}$. chiefly nurses, in the management of the patient. The specialised skills of nurses in particular have vastly increased, and no longer do the consider themselves the Nightingaliars hand-maidens. They and other staff are pressing to be involved in decisions regarding the management of patients? All the essayists agree that doctors ar 8 likely to remain, if not captains, the the leaders, but the nature of thein future role is uncertain.

I wonder, however, whether the physician is better portrayed as a pilot and the captain as the patient, asking receiving and usually accepting the advice from the pilot. Only once did find a mention of the fundamentas personal relationship between the patient and his doctor, to whom he comes for advice, and subsequently fo? help. He expects the doctors to suggese safe treatment and to protect him, fog instance, against administrators whלे perhaps may want to accelerate his 
discharge. The doctor is not, therefore, an autocrat on the bridge handing down commands to all around her.

If this is true, then it may be dangerous for the doctor to step out of this individual role and influence the medical care of groups of patients, because there will be conflict between, say, keeping his patient in hospital and pressures to shorten the average length of stay in hospital. Politicians forget that it is only too easy to practise cheap medicine, but that this may not be right.

The third relationship discussed in this book is that beiween the doctor and litigation over his actions. Many doctors believe that the increasingly vexatious patient will damage the trust between patients and their doctors and that this will impair standards of medical care. More legal action will force doctors to reconsider whether the risks to them (sic) justify carrying out potentially dangerous procedures. They can always decline to do so, and instead ask the patient to seek another opinion. Who benefits then?

Naturally there are no answers in this book, but I recommend practising doctors, and not just those interested in philosophy and ethics, to read this book. I found that some of the writing was neither simple nor clear and some words should not have been allowed to escape from the dictionaries. But this writing on the hospital walls should not be ignored by the profession.

R P H THOMPSON Consultant Physician St Thomas's Hospital London SE1 $7 E H$

\section{Explorations in Medicine: Volume 1}

\section{Edited by David Lamb, Teifion}

Davies, and Marie Roberts, 222 pages, Aldershot, £22.50, Gower Publishing Group, 1987

A major issue in contemporary philosophy of medicine is that of mechanism versus holism. In a mechanistic approach, the essential subject of medical theory is how the operation of physical processes results in functioning and malfunctioning of the various bodily organs; health is defined as the absence of disease, illness or injury; and the task of medicine is to relieve malfunctioning and suffering by removing its physical causes. In a holistic approach, the subject is the person as a whole, health is an ideal of maximum well-being and the function of medicine is not only to relieve injury and pain but also to increase personal autonomy. A crucial question for both theory and practice is which approach should be adopted, or, if they are combined, how exactly the synthesis is to be made.

The articles in this collection cover a range of topics in medical ethics and philosophy of medicine, but they have in common that they all to some degree defend or presuppose a holistic and person-centred approach to medicine. This is most explicit in the two papers by $\mathrm{E} \mathrm{K}$ Ledermann, the first of which argues that, while both approaches must be used, the holistic approach should be primary, while the second reinforces the point by showing how theories in medicine differ significantly from those in the purely physical sciences, such as astronomy. These papers are complemented by David Seedhouse's, which argues for a holistic concept of health, and by Ann Slack's, which describes some of the harm done by the excessively mechanistic approach of the 'medical establishment'.

Three other papers show, by implication, the need for a holistic approach to medical ethics, ie one that both respects individuals as persons and acknowledges that they are members of a wider social group. Thus Ruth Chadwick's paper criticises the Warnock Report for trying to deal with the ethics of reproductive technology without considering its effects on society as a whole. George Agich's paper argues that there are great difficulties in deciding what is a justifiable policy for genetic engineering if one relies on traditional or 'Rawlsian' considerations of justice (though it is unclear whether his conclusion is that we should reject genetic engineering altogether or that we should use a less individualistic ethical framework). And Bob Brecher seeks to demonstrate the impossibility of any morally neutral definition of mental illness, such as one based on lack of 'rationality', from which it would follow that even diagnosis has to consider the person in society.

The remaining three papers are concerned with applying the moral principle of respect for persons. Charles Dougherty derives from it ten criteria for 'morally acceptable research with human subjects', many of which have been all too often ignored. Heather Milne derives from 'a view of persons as "moral wholes"' a theory of the limits of permissible genetic engineering.
Finally, David Lamb examines 'the slippery slope' argument, that to permit abortion or to legalise euthanasia, even in limited and justifiable instances, would erode respect for human life, and argues that it fails in the case of abortion but is valid for euthanasia.

It should be added that the level of these papers is very high. Some are more concise than others, but every one of them is clear, interesting and worth reading. No reader is likely to agree with everything in them; but something can be learnt from them all.

HARRY LESSER Lecturer in Philosophy Dept of Philosophy, University of Manchester

\section{The Contraceptive Ethos: Reproductive Rights and Responsibilities}

Edited by Stuart F Spicker, William B Bondeson and $\mathrm{H}$ Tristram Engelhardt $\mathrm{Jr}, 254$ pages, Dordrecht, Holland, $£ 32.95$, US \$39, DF1 120.00, D Reidel Publishing Company, 1987

This book, part of a series on philosophy and medicine, contains thirteen papers presented at an American symposium entitled Reproductive Rights and Responsibilities: Medicine and the New Biology, held in 1983, and subsequently revised after discussion between authors and participants. The authors are American, mainly academics in medicine, philosophy, law, political science, sociology, history and population dynamics.

The book's introduction refers to 'the plethora of concepts germane to the new contraceptive ethos'. Some of the authors, however, question whether modern contraceptive technology has led to a new ethos about procreation, contraception, parenthood and population. This key question evokes a variety of responses. Most of the authors agree that sexual activity and contraception have to be seen in their social and moral context. The development of effective contraception has depended on contemporary cultural determinants, especially sexual attitudes and the socio-economic role of the female. Other factors influencing sexual behaviours are general population need, maternal and infant mortality rates, beliefs about 